\title{
Reensamblar la ciudad o cómo los estudios sociales y turisticos pueden influir la narrativa geo-socio-antropológica*
}

\author{
Fernando Nava La Corte \\ Universidad Autónoma del Estado De México, Toluca, México \\ ferlacorte0@gmail.com
}

\section{RESUMEN}

El presente trabajo busca exponer algunas maneras de apropiación espacial en la zona turística de la comuna trece en Medellín, Colombia. Esta exploración se hace teniendo en cuenta el uso que las personas tienen del lugar en relación con su organización espacial, la disposición del mobiliario en el espacio y su inserción urbana. Así mismo, la aproximación metodológica que se plantea es de carácter cualitativo y el trabajo de campo empírico está circunscrito al universo narrativo con el que se busca explicar qué hace familiar un lugar y para quién es familiar ese lugar, lo que lleva a revelar los grados de integración y disuasión que existen en el espacio.

En esta vía, el objetivo del presente documento se enfoca en identificar cuáles han sido los impactos socioculturales en el área de amortiguación ocasionados por la actividad turística. Para ello, se analiza la teoría del habitar, la información clave a partir de los recorridos turísticos

que se ofrecen, la observación participante y las entrevistas a diferentes actores del lugar que permitieron hacer una recopilación de datos y los testimonios que abonaron a la revisión crítica. Las conclusiones muestran que no hay solo un antes y un después, o una sola imagen capaz de abarcar toda la comuna, lo que sí existe son modos de ver y narrar la comuna trece. De igual manera inferimos que las políticas turísticas y territoriales regionales propician un desarrollo para las comunidades nativas, pero, siguen existiendo niveles de desigualdad social y polarización socioespacial. No todo está perdido en la comuna trece en Medellín Colombia; pues el grafiti de varios artistas nacionales e internacionales testifica y conmemora lo vivido en el barrio como punto medular de una transformación socioespacial permanente.

Palabras clave: impactos socioculturales; comunidades; turismo; grafiti; narrativas.

Cómo citar: Nava La Corte, F. (2021). Reensamblar la ciudad o cómo los estudios sociales y turísticos pueden influir la narrativa geo-socio-antropológica. Ciencias Sociales y Educación, 10(20), 45-62. https://doi. org/10.22395/csye.v10n20a3

Recibido: 10 de marzo de 2021.

Aprobado: 13 de mayo de 2021. 


\section{Reassembling the City or How Social and Tourism Studies can Influence the Geo-Social-Anthropological Narrative}

\section{ABSTRACT}

The present work seeks to expose some ways of spatial appropriation in the tourist area of the thirteenth commune in Medellín, Colombia. This recognition is made from the relation that people have with the place, in regards to its spatial organization, the arrangement of furniture in space and its urban insertion. Likewise, the methodological approach that is proposed is of a qualitative nature and the empirical field work is limited to the narrative universe with which it seeks to explain what makes a place familiar and for whom that place is familiar, which leads to reveal the degrees of integration and deterrence that exist in space.

In this context, the objective of this document is focused on identifying what have been the sociocultural impacts in the buffer area caused by tourist activity. For this, the theory of inhabiting, key informants from the tourist tours that are offered, participant observation and interviews with different actors of the place that allowed a compilation of data and testimonies that they paid for the critical review are analyzed. The conclusions show that there is not only a before and after, or a single image capable of encompassing the entire commune, which if it exists are ways of seeing and narrating commune thirteen, in the same way regional tourist and territorial policies favor development for native communities, but there are still levels of social inequality and socio-spatial polarization. Not all is lost in commune thirteen in Medellín, Colombia; since the graffiti of various national and international artists testifies and commemorates what has been lived in the neighborhood as a core point of permanent social-spatial transformation.

Keywords: social-cultural impacts; communities; tourism; graffiti; narratives.

\section{Remontando a cidade ou como os estudos sociais e turísticos podem influenciar a narrativa geo-socio-antropológica}

\section{RESUMO}

O presente trabalho procura expor algumas formas de apropriação espacial na área turística da décima terceira comuna de Medellín Colômbia, este reconhecimento é feito a partir do uso que as pessoas têm com o lugar, em relação à sua organização espacial, a disposição dos móveis no espaço e sua inserção urbana. Da mesma forma, a abordagem metodológica que se propõe é de natureza qualitativa e o trabalho de campo empírico limita-se ao universo narrativo com o qual procura explicar o que torna um lugar familiar e para quem esse lugar é familiar, o que leva a revelar os graus de integração. e dissuasão que existem no espaço.

Neste contexto, o objetivo deste documento está centrado em identificar quais 
têm sido os impactos socioculturais na área de amortecimento causados pela atividade turística. Para isso, é analisada a teoria do habitar, informantes-chave dos roteiros turísticos que são oferecidos, observação participante e entrevistas com diferentes atores do lugar que permitiram uma compilação de dados e depoimentos que pagaram pela revisão crítica. As conclusões mostram que não existe apenas um antes e um depois, ou uma imagem única capaz de abarcar toda a comuna, que se existe são formas de ver e narrar a comuna treze, da mesma forma que as políticas turísticas regionais e territoriais favorecem o desenvolvimento dos indígenas. comunidades, mas ainda existem níveis de desigualdade social e polarização socioespacial. Nem tudo está perdido na comuna treze em Medellín, Colômbia; já que o graffiti de vários artistas nacionais e internacionais testemunha e comemora o que tem sido vivido no bairro como um ponto central de permanente transformação socioespacial.

Palavras chave: impactos socioculturais; comunidades; turismo; graffiti; narrativas.

\section{Introducción}

En la actualidad, el desarrollo de las ciudades y de los lugares se asemeja cada vez a un pastiche donde la idea de expansión y de progreso los hace caóticos. En este contexto de entropía coexisten en una misma calle urbanizaciones con todos los servicios públicos. Paralelamente, existen barrios en donde no se tiene acceso al agua y se deja terreno libre a la comida rápida en lugar de promover la comida regional. Además, hay comunas que cuentan con escaleras eléctricas de tipo centro comercial como una forma de intervención socioespacial de vanguardia.

Para dar cuenta de lo anterior, realizaremos un análisis científico transdisciplinario encaminado a la producción y al estudio de los espacios y territorios geográficos sociales —en sus diversas escalas-, identidades y (de)construcciones significativas a partir de la tensión local-global. Investigar con estas intenciones no es fácil cuando se llega con preguntas que persiguen traspasar el umbral de lo supuesto y lo obvio; por consiguiente, para acercarnos a este proceso complejo y actual de la sociedad y de los lugares, requerimos tener una apertura al juego entre lo homogéneo y lo fragmentado, así como las combinaciones y desuniones de paisajes cotidianos.

Según lo acostumbrado, la tradición investigativa clásica, en su interés por examinar los modos y los medios en donde interaccionan y viven las personas en los lugares, recurren a técnicas como: los censos, los sondeos y la estadística como técnica cuantitativa por excelencia y casi siempre desde la mirada de la ciudad proyectada, objetiva y organizada a la cual se le conoce como la ciudad o el lugar construido; pero hay otro elemento que tiene que ver con la experiencia del lugar que no ocurre en los objetos tangibles, sino en las percepciones de 
quienes lo padecen o viven, es decir, existe un lugar vivido. Este último aspecto nos permite pensar en un diagnóstico alterno con el cual se privilegian otras maneras de búsqueda que sepan aprehender los datos a partir de las (inter) acciones con el espacio, estas asociaciones en objetos o insignias a través de los cuales se pueden escudriñar los temores, los anhelos, las negaciones y las narrativas de los individuos por la asimilación de su espacio.

De acuerdo con lo anterior, Rivas y Mercerón (2020) señalan que las narrativas permiten hacer énfasis en la comprensión de historias vivenciales de una realidad dada, así como reflexionar sobre estas historias y, posteriormente, explicarlas a los demás. Vale la pena señalar que no solo se trata entonces de que los actores sean narradores de su vida y su contexto, sino que al compartir su experiencia refuerzan un sentido histórico y toman conciencia del valor de su existencia. Así pues, esta investigación se encuentra relacionada con estudios que examinan las representaciones propias de la cultura socioespacial contemporánea, de manera que, se está en un vaivén de planteamientos clásicos y posmodernos (nos referimos al movimiento intelectual) que vinculamos con el ánimo de tener en cuenta dos corrientes intelectuales que nos permitan vislumbrar la copresencia de realidades heterogéneas con el afán de dilucidar los mecanismos o las disposiciones del espacio causales que sirvan para explicar los fenómenos parcialmente.

A partir de un contexto complejo, se comienza a (re)considerar el papel de lo social y lo espacial como parte de un colectivo, dando lugar a una visión integral del espacio (rescatar esta noción de integralidad representó una constante durante esta investigación). Es por esto que al nombrar el concepto de lugar nos referimos a la ciudad, la comunidad, el barrio o la localidad; se resalta además que cada concepto depende de la percepción que tengan los diferentes actores en su papel de visitantes, investigadores o residentes. Fue de importancia para esta investigación involucrar las prácticas proyectuales desde el ámbito del diseño para incidir en la realidad y en la complejidad de los lugares, de este modo, a partir de la comunicación participativa y del análisis, tomamos postura como actores en la realidad especifica en la que se concentró esta investigación, esto es, en la comuna trece de Medellín. Reconocimos cómo sus elementos representativos de identidad, espacio y sociedad ayudan de manera pertinente a su visibilización. Este proceso de transformación permanente en los espacios, no puede ser solo tarea de los grupos que las habitan o de una sola profesión; por el contrario, es preciso una labor trans (inter)disciplinaria en la que la mayoría de los actores del colectivo pueda inmiscuirse. Necesariamente los actores tienen que estar atentos a conocer los cambios sociales, los comportamientos de los visitantes y los demás factores del espacio para maximizar el acervo cultural y simbólico que configura la identidad de la comuna trece. 
La apuesta de este trabajo es identificar y considerar las disposiciones del espacio por parte de los diferentes actores comentados anteriormente, y que con sus características de expresión, transformación y realidad influyen sobre este actual modelo de integración identitaria y relacional, por lo que para su conocimiento se aplicaron las siguientes unidades de socioanálisis: el reconocimiento, la pertenencia, la permanencia y la vinculación. Estas unidades permiten mostrar los derroteros que fomentan la participación de narrativas y espacios bajo la premisa de utilizar un lenguaje que les sea común. Cabe mencionar que se trabajó con las particularidades y las circunstancias de cada elemento del colectivo y su relación entre sí, principalmente, en lo concerniente a las tensiones identitarias, sociales, materiales y espaciales. Siguiendo esta estela, se trató de un sistema complejo donde confluyeron homogeneidades, heterogeneidades, contextos globales y locales; la correlación se alcanzó debido a las múltiples conexiones del sistema que permitieron el intercambio de elementos culturales, sociales, económicos entre otros, y que propiciaron nuevas formas de percibir, concebir y vivir el espacio. Cuando se logró esta interrelación recursivamente, se identificó una entropía positiva, es decir, la producción de sentido que hay en el interior de cada uno de los subsistemas y su correspondencia con los otros.

Haremos referencia a sitios en devenir como la comuna trece en Medellín que, marcados por acontecimientos de historicidad, se vuelven modelos de transformación socioespacial de alguna región o pueblo. Esta perspectiva resulta congruente a los fines de establecer relaciones que nos permiten comprender cómo los actores sociales, a partir de sus narrativas personales y colectivas, han finalmente conformado una dignificación barrial pertinente. Estos sitios como la comuna trece cuya memoria subyacente es más significativa que el propio lugar físico y donde tanto el presente inmediato que engloba necesidades como la educación, comunicación, derecho popular y emprendimientos encuentran un importante diálogo en la juventud, misma que muestra al mundo intervenciónes artísticas a través del grafiti. García (2009) habla de una ciudad histórica, de barrios, de monumentos en donde se interrelacionan las costumbres y los usos de sus habitantes para así documentar su evolución, su proceso histórico y las actividades económicas que se desarrollan en la ciudad o en diversos sectores industriales que manifiesten su esfuerzo por crecer económicamente, pero el autor también habla de la existencia de una ciudad globalizada que se relaciona con las redes mundiales de las finanzas, la economía y las comunicaciones. El llamado graffititour en la comuna trece de Medellín se enmarca en un vaivén de historicidad y globalización e implica el acercamiento de los otros hacia espacios desconocidos. Estos actores externos o extranjeros disfrutan de la contemplación de los hitos, de las narrativas y del grafiti, siendo este último, una intervención con gran poder de evocación y de (re) significación de la comuna trece. El recorrido que brinda el colectivo denominado 
Casa Kolacho ${ }^{1}$ provoca en el actor externo esa misma mirada nostálgica de cualquier nativo de la comuna al recordar el pasado.

\section{Discusión-reflexión}

Una forma de comprender la dialéctica socioespacial para García (2009) es a través del uso de metáforas en las imágenes y en las narraciones para de esta forma reflejar lo que el entorno global tiene de utopía y lo que no puede totalizar, por ejemplo, las diferencias entre europeos y latinos o los desarraigos de la gente que viaja o cambia de país y de residencia. Estas metáforas sirven para imaginar lo diferente y las narraciones ritualizadas, para ordenarlas.

Este impacto es evidente en los procesos geográficos, sociales y antropológicos a escala mundial, pues más allá de un desvanecimiento de las tradiciones y costumbres, prevalecerá la falta de un reconocimiento identitario que contenga los parámetros que contribuyan a una proyección incluyente; por lo que será menester comprender a través de qué dinámicas los lugares como la comuna trece aseguran su pervivencia de arraigo y no de transitoriedad en el contexto urbano de Medellín. ¿Cuál es la especificidad que aporta el mobiliario urbano y las prácticas cotidianas en el espacio? ¿Y en qué medida una determinada apropiación puede (des)configurar un horizonte social de sentido compartido?

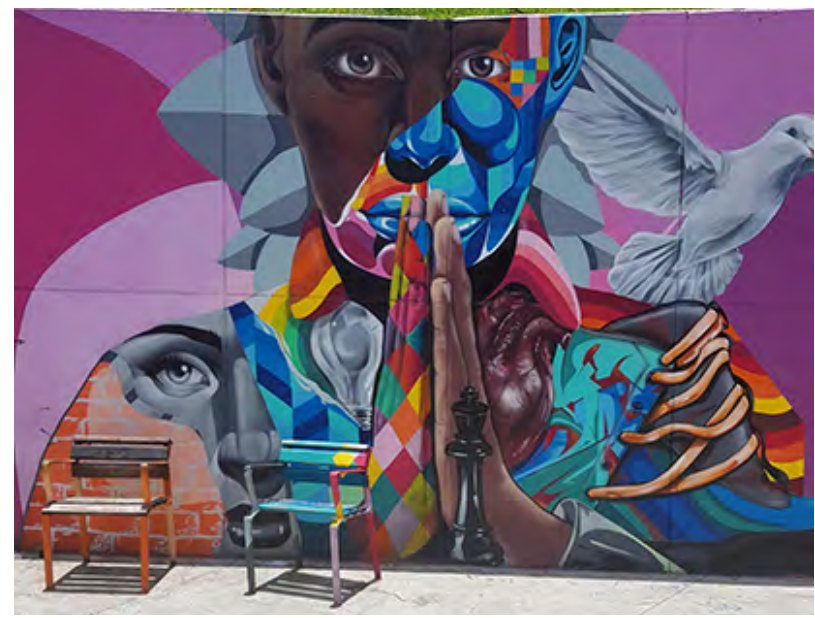

Imagen 1. Expresiones artísticas del graffititour en la comuna trece de Medellín. Colombia

Fuente: Fernando Nava La Corte, archivo personal, año 2018 .

Centro que conmemora a Héctor Pacheco "Kolacho" líder por excelencia que apoyaba el arte y la cultura como alternativa a la criminalidad. Actualmente a este centro le dan vida grafiteros, Djs, fotógrafos, grupos musicales y bailarines. 
El hecho de tratar de reconocer la peculiaridad de cada articulación espaciotemporal específica, permitirá examinar y contemplar un proceso multidimensional, producto de factores estructurales activados por los actores sociales y atravesado por la dialéctica de lo global y lo local.

La hibridación se piensa como un fenómeno indefectiblemente asociado a la modernidad, tal y como esta se configura en la lógica del mercado productor de consumidores y rearticulador de identidades ciudadanas en la globalización y en las intersecciones entre la cultura de elite, la industria cultural y la cultura popular. (Szurmuk y Mckee Irwin, 2009, p. 134)

Se debe entender ese carácter fragmentado o hibrido de vivir con un pie en lugares que desean ser reconocidos, y que lo ejemplifican a través de su consumo turístico, y con el otro pie en la resistencia, la desigualdad y la marginación que, por contraste, se podría considerar innovación urbana.

Es necesario precisar este término de turismo como proceso social, según Hiernaux (2000) es un sistema de actores, de prácticas y de espacios que participan de la recreación de los individuos por el desplazamiento y el habitar temporal fuera de los lugares de lo cotidiano. Entonces, el turismo es una práctica de desplazamiento y de habitar lo itinerante; es productor, transformador y consumidor de los territorios al implantar un sistema de estímulos como pueden ser imágenes, representaciones e intervenciones de vanguardia y estilos de vida propios que de alguna manera, al igual que otros fenómenos sociales, conjuga a su modo la oposición de lo local y lo global (Bustos, 2001).

Con lo anterior, se alude a que vivimos en un mundo en el que los criterios de confort, lujo o sofisticación uniformizan lo cotidiano y que el turismo es una actividad de ocio limitada en el tiempo. La imagen que deben proyectar los lugares turísticos debe ser una imagen depurada ${ }^{2}$ tal y como se muestra en las agencias turísticas, folletos e internet. La revisión sobre la tesis del turismo en este trabajo abona a la revisión crítica de la comuna trece en Medellín que se abordará adelante. Esta postura nos deja ver que los lugares son cada vez más intercambiables entre sí, con nuevas señas de identidad y que propician una transformación del lugar, en las que los referentes simbólicos e imaginarios heredados se hibridan con otros procedentes de distintas culturas.

Haremos énfasis en que un rasgo peculiar actual en la transformación de los lugares es a causa de un turismo masificado en donde al menos la mayoría de personas espera salir de vacaciones y con esto equilibrar su vida rutinaria, con esto, la mirada del turista impone sobre los lugares que visita la imagen de su deseo (lo que espera encontrar y corroborar para no decepcionarse). La noción

Término propuesto en el texto que infiere a la comodidad de disfrutar un lugar sin temor; además de ofrecer el consuelo de pertenecer. 
del turismo podría evocar entonces la visita de una ficción poblada de copias; la pugna, no solo para la disciplina sino para el lugar y sus habitantes será resaltar lo real de la ficción o generar una ambivalencia acorde, pues cada vez se enfrenta a un simulacro más realista.

El hombre, al desarrollar su vida en varios escenarios, ejerce sobre el espacio una transformación que explica su propia existencia de diversas maneras. Esto lo constituye como un ser histórico con un pasado y un sentido del futuro que desarrolla actividades como miembro de una sociedad, y que se relaciona e identifica con sus componentes contribuyendo al mantenimiento de su grupo para asegurar su continuidad. Todo este contexto de espacio, medio ambiente, tiempo y relaciones sociales es lo que constituye su cultura.

García (1997) señala que los espacios actuales son como un videoclip o como montajes efervescente de imágenes discontinuas; al igual que en un videoclip, caminar por los lugares implica mezclar experiencias, imágenes y distintas realidades que compiten arduamente para lograr captar la atención de visitantes o residentes. Pensemos por un momento en un lugar específico de la comuna trece de Medellín Colombia en donde, con un grafiti multicolor, una arquitectura brutalista en ladrillo rojo y con colores verde montaña —tensión y paradoja-, se celebra y afirma que los lugares son cada vez más diversos en el sentido de que hay una tendencia a emancipar al individuo, al mercado, a la cultura y a imponer un poder siempre más palpable que posibilita el arraigo simbólico-afectivo en relación con el lugar donde el individuo vive y se desempeña.

\section{Método e instrumentos}

Teniendo como premisa la idea de lo cotidiano que desarrolla De Certeau (1998), la cual sostiene que lo ordinario es una construcción social del espacio que presenta una alternativa de ver la ciudad con su desorden, espontaneidad y diferencia, podríamos asentir que es posible rastrear múltiples maneras de conexión entre los conceptos de producción y construcción social del espacio. El espacio entonces es permeado y fundamentado por las relaciones sociales y es producto de ellas (Lefebvre, 1991).

Los apartados anteriores nos han permitido identificar algunas vicisitudes y resonancias de los lugares, no solamente dentro de una categorización turística determinada, sino también como lugares pluridimensionales con necesidades diversas que se convierten en el principal motor de la transformación espacial, económica, cultural y social. Un punto de partida para adentrarnos en la complejidad del espacio consiste en circunscribir los textos de Lefebvre (1991) con lo que llama el espacio físico, espacio imaginado, espacio abstracto; el espacio físico se refiere a un espacio relativamente objetivo y concreto. El 
espacio Imaginado se refiere a las ideas acerca del espacio, a las construcciones mentales creativas del espacio. Finalmente, el espacio abstracto combina las dos primeras formaciones, de las que resultan nuevas formas de subjetividad, y representa las experiencias cotidianas de las personas en el espacio. Por lo tanto, las relaciones sociales y el espacio abstracto están indisolublemente unidos en la vida diaria. En este sentido, la producción del espacio urbano abarca mucho más que solo planear el espacio material de la ciudad, pues este incluye también la producción y la reproducción de todos los aspectos de la vida urbana.

La comprensión y el análisis de las características espaciales de la comuna trece y de otros elementos que la componen, tienen el propósito de sentar las bases para la comprensión de sus transformaciones en cuanto a la forma y la función en relación con sus actores. El espacio es para la sociedad el centro de funcionamiento de la democracia, la civilidad y la interacción con los otros, de manera que, el presente apartado pretende, a través de herramientas etnográficas, comprender algunas maneras de apropiación que hay en la comuna trece de Medellín, a partir del uso que las personas tienen respecto de las disposiciones del lugar; la relación de los cuerpos, los objetos y las cosas nos permitirán reconocer estas prácticas culturales tan diferentes y tan distintivas del colectivo.

El ser en una determinada espacialidad, propio de las identidades colectivas, indica de entrada una relación con los otros y una ubicación en el espacio con los otros, los suyos [...] No es solo ocupar un lugar en el espacio. El habitar significa poseer, producir, crear. (Tamayo y Wildner, 2005, p. 46)

Con lo anterior, asentimos, por un lado, que la espacialidad se construye a partir de ordenamientos precisos con impacto positivo sobre su contexto; y por otro lado, que es el instrumento que tensiona la temporalidad. Dirige los procesos hacia el futuro y disminuye los grados de incertidumbre que existen en la sociedad contemporánea.

En este trabajo se propone comprender la espacialidad como la cualidad o el grado de lo compartido por un colectivo que se construye con nexos inteligibles por la mayoría. Se trata pues, de superar una arquitectura del distanciamiento favoreciendo la relación cultural e identitaria.

Tan solo la ubicación de cosas en el espacio ya tiene un sentido, más aún la ubicación de las personas. Por ello los espacios dejan de ser objetos para convertirse en "espacialidades" con un sentido y un valor determinado. (Tamayo y Wildner, 2005, p. 46)

La identidad en los lugares no es un hecho meramente notorio, no es una verdad objetiva que aparece de forma palmaria y fehaciente en la realidad, sino una (re) construcción analítica. Y, es ahí donde a veces se encuentra la dificultad 
porque cualquier observación puede, en apariencia, delimitarse bajo el tamiz de la identidad y justificar un comportamiento y un rol social. La identidad no es un hecho estático y la mayoría de las veces se expresa de forma dialéctica y compleja. Tamayo y Wildner (2005) consideran cuatro componentes esenciales para describir el proceso complejo que implica la identidad: - reconocimiento, pertenencia, permanencia y vinculación-. El objetivo de puntualizarlos en este trabajo reside en comprender el sentido de familiaridad o disuasión de las personas con los lugares. Esta (des)apropiación, en todo caso, expresa las pautas socio-culturales-políticas entre otras, que operan individualmente y como asociación.

A continuación, se abordan estos cuatro componentes esenciales. El objetivo de puntualizarlos en este trabajo reside en comprender el sentido de familiaridad o disuasión de los diferentes actores con la comuna trece en Medellín Colombia, ya que los espacios en su dinámica actual, cambian, se crean, se modifican y se extinguen muchas veces por presión de sus usuarios, y otras, por la incomprensión de los actores externos.

\section{Reconocimiento}

El reconocimiento es comprendido como el sentido de autenticidad, como la conducta individual que me autoidentifica y autodetermina, es decir, de reconocerse a uno mismo y decir, me reconozco y me reconocen. "Es el sentido de quién se es y cuál es la relación de mí con los otros" (Tamayo y Wildner, 2005, p. 17). Por su parte, la identidad es la construcción de un distintivo, como algo singular y original que puede tener dimensiones subjetivas y objetivas. Esta se puede comprender a través de conductas, interacciones y objetos, así como de narrativas e interpretaciones que son acuerdos sociales que se fabrican y se relatan junto a un tiempo y un espacio determinado.

En los espacios, si se quisiera definir su autenticidad, se tendría que considerar la relación existente entre el hombre y los elementos que este utiliza para construir su medio, en este sentido cabe mencionar que las personas prefieren aquellos signos que le resulten más evocadores y tranquilizadores.

Uno de los casos de interés en este trabajo es el de las escaleras eléctricas, pues esta experiencia de recorrer el lugar a través de ellas es algo muy diferente. Su experiencia implica la sensación de ser transportado a otro lugar, las escaleras eléctricas, a diferencia de las "escaleras de cemento" de hace años, pueden estar en la comuna (regularmente construido física y simbólicamente) pero no forman parte de ella, no son del contexto habitual, sino de un mundo totalmente "otro". Esta "realidad" provoca cierta percepción de un 
espacio paradójico pues aunque tenga gran afluencia de extranjeros, dicha intervención moderna ha modificado los modos de vida actuales.

La expresión recurrente "me gusta visitar este tipo de lugares por ser seguros y muy turísticos" (Casa Kolacho,10 de Septiembre de 2018) ${ }^{3}$ refleja la correspondencia sujeto-objeto; esta conexión es la que hace posible el análisis del paisaje subjetivo y todo estudio sobre el modo de ver del sujeto va precedido de una tipología de los elementos que conforman su hábitat.

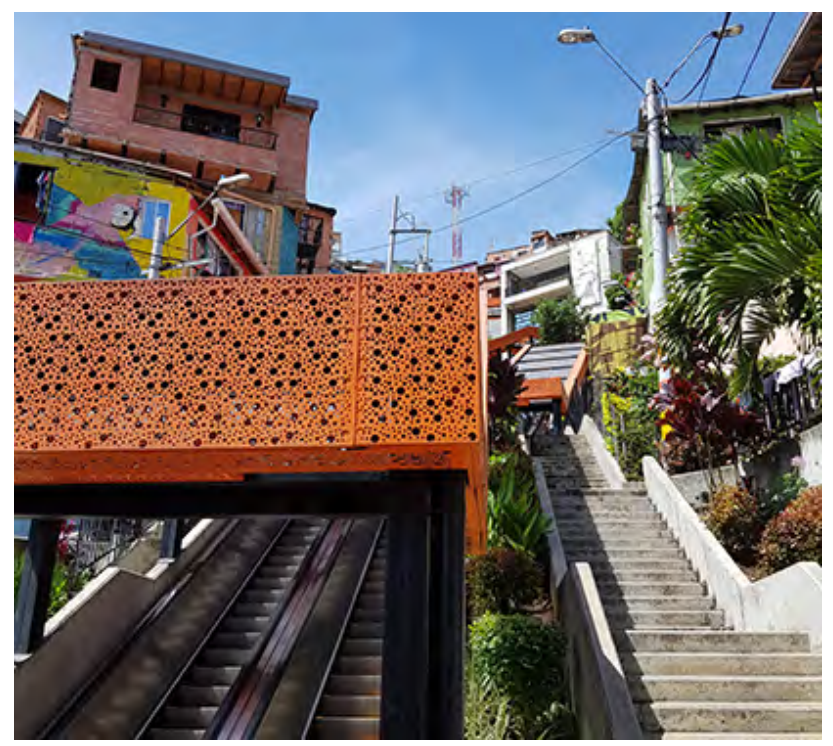

Imagen 2. Diferentes formas de pensar el espacio, Comuna trece Medellín. Colombia

Fuente: Fernando Nava La Corte, archivo personal, año 2018.

\section{Pertenencia}

La pertenencia es el segundo componente y significa tener el dominio de algo, incluso de uno mismo "es el proceso de situarse y al mismo tiempo de poseer, apropiarse de las cosas, del espacio" (Tamayo y Wildner, 2005, p. 19). En tal sentido, si el reconocimiento está asociado al ser, la pertenencia está asociada al estar en un lugar; por lo tanto, significa apropiación del espacio. Estar en un lugar produce distintos niveles de arraigo y afecto, esta condición es visible en ejemplos cotidianos de personas en situación de calle o que venden golosinas en las esquinas, es decir, toman a la calle como gran "espacio cerrado en

3 Las respuestas y expresiones obtenidas en este trabajo se manejan a nombre del colectivo casa Kolacho como una forma de expresión incluyente y recurrente en la realidad inmediata de la comuna trece en Medellín Colombia. 
plano abierto". En cada uno de estos ejemplos citados se observan no uno, sino muchos roles y un trajín de identificarse a sí mismos o describir el lugar para destacar sus características, el rol o el papel social del individuo son conductas que se adoptan y, por ello, ese papel es expresión de identidad.

Los habitantes de la calle muchas veces se asocian a un imaginario de gente peligrosa o criminal, pero también es posible pensar que estas personas se ven forzadas a renunciar a su humanidad por las condiciones de pobreza y de desigualdad que provocan las urbes. Experimentar las condiciones en las que viven estas personas como dormir en albergues abyectos, en frías y duras banquetas, realizar trabajos denigrantes y mal pagados o alimentarse de restos de comida de los botes de basura representa, sin lugar a dudas, otra estirpe identitaria, una que anda sola y aglutinada, y que es, simultáneamente, resultado del fenómeno de las megalópolis.

Esta posesión del lugar la vemos reflejada también en un sinfín de ejemplos cotidianos en la comuna, como la imagen que muestra el sentido de pertenencia que tienen las personas a sus negocios, la persistencia de resignificar el territorio a través del grafiti y en la bienvenida que dan a los otros, tal es el caso del siguiente enunciado que profería un integrante del colectivo: "el territorio también se ha autogestionado, se ha consolidado un trabajo, pero a futuro se avizoran otros conflictos" (Casa Kolacho, 7 de Octubre de 2018). Con lo anterior obtenemos que los actores al (re)conocer el lugar y su historicidad tienen capacidad de generar trabajo dentro de la comuna trece, pero más que eso es la conmemoración per se, es la pertenencia de ellos ante los externos.

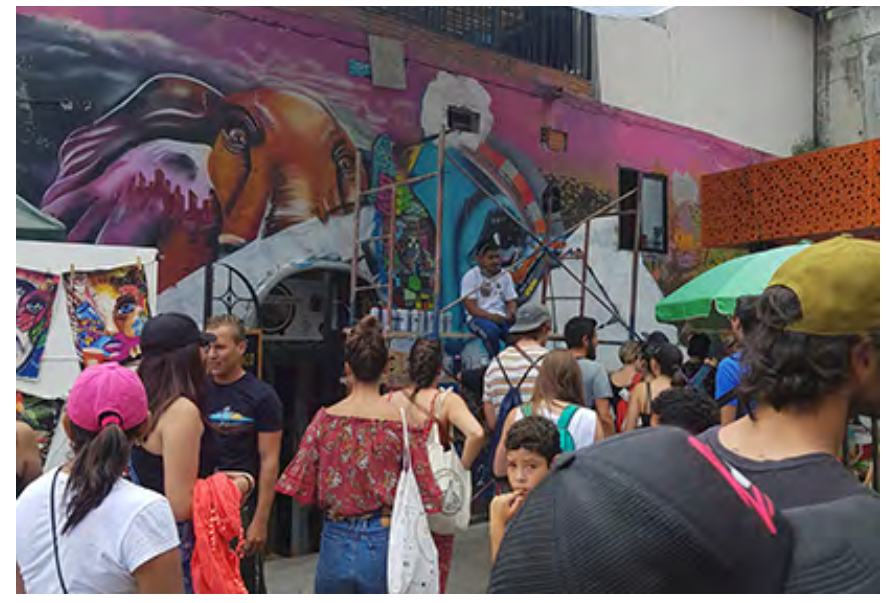

Imagen 3. Muestra de grafiti en vivo y venta de souvenirs en la comuna trece Medellín. Colombia

Fuente: Fernando Nava La Corte, archivo personal, año 2018. 


\section{Permanencia}

La permanencia se relaciona de manera precisa con el tiempo y la duración de estar en un lugar, lo cual comunica diferentes niveles de arraigo. La permanencia está ligada también al concepto de cotidianeidad y se refiere a la constancia, a la regularidad y a la persistencia de una rutina. Refiere además que la vida cotidiana es el lugar donde se lleva a cabo la mayor parte de nuestra existencia, es el tiempo y el espacio lo que nos define y constituye nuestra identidad.

La permanencia se manifiesta en las rutinas porque se está en un espacio y en un tiempo determinado. Ella produce la posibilidad de compartir el enfoque transformador y de resistencia del lugar con los otros. Ante tal aclaración nos encontramos con el hecho de que estas articulaciones afianzan la continuidad del impacto e integración social de la comuna trece. Es importante separar de forma metódica este concepto de permanencia para comprender la fuerza de supervivencia de las identidades; a la par, es menester tener en cuenta que las identidades, aun cuando parezcan estables, son productos de procesos dinámicos y asociativos.

Teniendo en cuenta lo anterior, asentimos que la temporalidad y la corporeidad en un espacio determinado crean la lugaridad. Este término implica familiaridad y ensamble con el entorno, conexión que se logra a partir de la experiencia y la asignación de significado.

Estas relaciones e interrelaciones que guardan entre sí los subsistemas "con ellos mismos y su alrededor", y que de manera gradual se descubren, son las que constituye puntos valiosos en el presente texto que no pueden ser tangenciales. La construcción social del espacio, vista en relación con la producción social, hasta cierto punto combinada y sobrepuesta, apuntala las concepciones de De Certeau (1998) con las que sostiene que la lugaridad es la construcción física y social del lugar. Esto tiene sentido a través de la interacción entre el usuario y el espacio. Dentro de este universo de narrativas, un integrante del colectivo casa Kolacho menciona que, "a través del grafiti conmemoramos el pasado y a todas aquellas personas que ya no están con nosotros para la trasformación social... es un homenaje" (Integrante Casa Kolacho, comunicación personal, s. f.). 


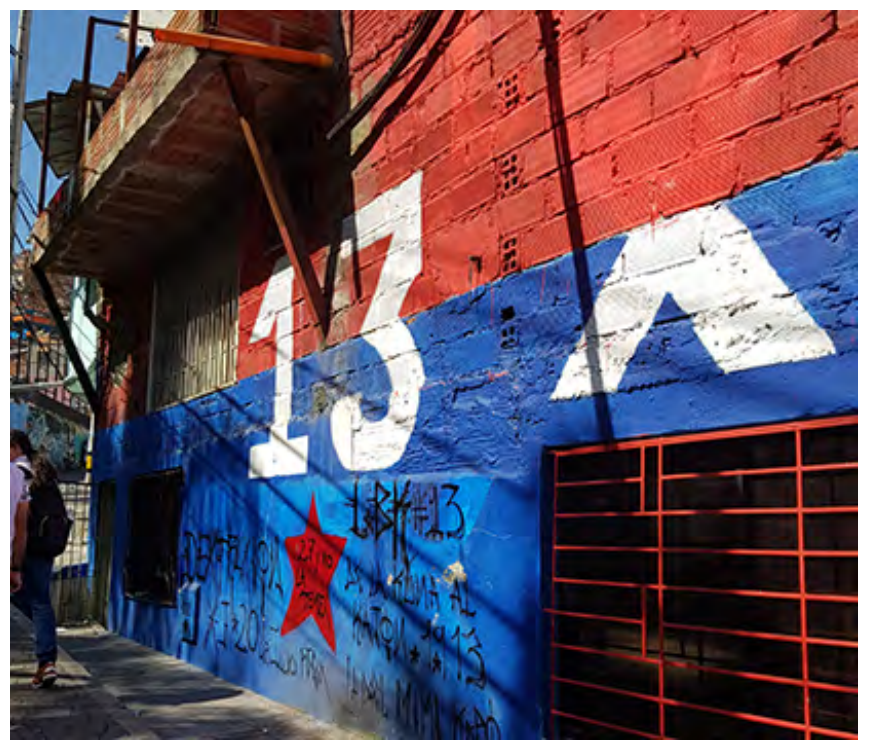

Imagen 4. Historicidad en las calles de la comuna trece Medellín. Colombia

Fuente: Fernando Nava La Corte, archivo personal, año 2018.

\section{Vinculación}

La vinculación es el cuarto componente de la identidad y puede definirse como una asociación en la cual los participantes obtienen beneficios del encuentro ya sean construcciones simbólicas, políticas o de orden económico. Este comportamiento es reconocible al instante cuando escuchamos expresiones recurrentes como: "mi comuna" o "mi barrio" y, es este sentido de raigambre o de nostalgia que promueve varias perspectivas cambiantes sobre los lugares en donde se descubren nuevas maneras de ver la realidad. $Y$, es precisamente con respecto a este carácter fluctuante que Claudia Pedone (2004) logra concebir una constitución de redes de vecinos y parientes como una fuente de información que otorga una cierta seguridad para promover la migración. Esta dinámica de posibles oportunidades, aunada a más factores, explica las causas del exilio. No obstante, con la llegada al lugar de destino, el sentido de vinculación con el terruño es algunas veces más importante que las condiciones de trabajo que buscan tener o el alto grado de precariedad de vivienda a la cual se enfrentan a su llegada.

Como vemos la vinculación se da de múltiples formas. El vínculo puede ser a un lugar o una persona, por mencionar algunos ejemplos, y es reconocible al instante porque las asociaciónes culturales e históricas que acontecen en la comuna trece posibilitan una relectura del espacio con el arte urbano. Este intercambio simbiótico se convierte en un valor por sí mismo en los rituales, ya 
sean sagrados o seculares. La vinculación también puede ser (in)formal, pues las personas que "disfrutan el tiempo" en las esquinas de un pueblo cualquiera, que toman cerveza o café junto a otras personas, intercambian chismes o vida de barrio, inconscientemente "están vinculados" al espacio o a los otros; tales actos están envueltos en la experiencia del placer mutuo.

Este componente de vinculación expresa con claridad el sentido de pertenencia a un grupo, a una red o a una institución. Y también se apropia de ideas y valores que son comunes de la colectividad. Es una forma de integrar y asimilar, y en ese sentido hay un proceso - explícito o implícito, dependiendo del tipo de identidad que se trate- de reproducción de la identidad que asegura la asimilación y su mantenimiento. (Tamayo y Wildner, 2005, p. 21)

Dentro de estas manifestaciones artísticas, la comuna trece se convierte entonces en un punto de encuentro entre turistas y residentes que facilita percepciones y convergencias diversas para la cohesión social. Así pues, la correspondencia social y simbólica marca el proceso en el que los actores sociales comparten significados. En el centro de lo anterior se encuentran los conceptos de producción y construcción social del espacio. "El espacio social incorpora las acciones sociales, las acciones de los individuos y grupos que nacen y mueren, que sufren y actúan" (Lefebvre, 1991, p. 3).

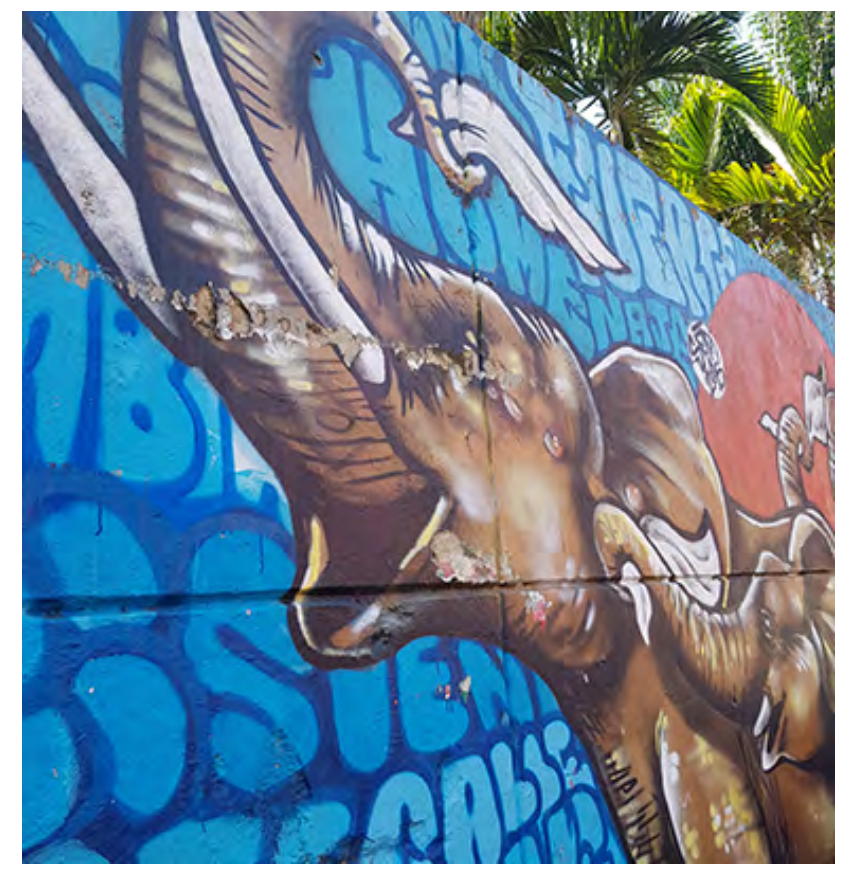

Imagen 5. Grafiti en los muros de la comuna trece Medellín, Colombia.

Fuente: Fernando Nava La Corte, archivo personal, año 2018. 
Con lo anterior, se pueden dilucidar algunos componentes identitarios de los lugares, pero en realidad estos siempre aparecen en conjunto ya sea en las personas, los lugares o en la memoria. Una imagen del espacio sobresaliente requiere siempre en primer término la identificación, lo que implica su distinción con respecto a otras cosas y su reconocimiento como entidad. A esto es lo que se define con el nombre de identidad, no en el sentido de igualdad con otra cosa, sino con el significado del lugar.

La relevancia de profundizar en estas narrativas geo-socio-antropológicas a partir de estas unidades de análisis sugeridas, está en la posibilidad pensar el desarrollo y la cohesión socioespacial como elementos que generan modelos de integración identitaria en otras latitudes. Dicho lo anterior, el presente trabajo también expresa la voluntad de mantener la esencia de un lugar, buscando impulsar con esto la participación social, su diferenciación con otras entidades y organizar una identidad de acuerdo a símbolos y memoria histórica.

\section{Conclusiones}

De acuerdo con los alcances mostrados en este trabajo se tiene que, al recorrer la comuna trece de Medellín nos encontramos con una propuesta de participación encarnada por los actores externos, que apunta a una propuesta cotidiana de poder recorrer cualquier lugar, aunque este no goce de una categoría socioespacial implantada por símbolos de consumo meramente turísticos. Actualmente para la comuna trece no es menester integrar una noción mercadológica innovadora, pues es más importante resaltar la oportunidad de existir y compartir con los otros, aunque esto último pareciera superfluo, al menos es más real en términos de dignificación histórica barrial. La propuesta está vinculada a lo múltiple y al movimiento, al contacto con otras personas, objetos o cosas, y son estas cosas las que construyen una narrativa temporal y una proyección de futuro; además de destacar la importancia de las relaciones sociales, se privilegia las disposiciones en el espacio de los demás objetos, cosas y cuerpos, con el fin de reconocer las prácticas culturales del colectivo.

Por otra parte, las memorias del habitar son construcciones intersubjetivas asociadas con procesos de apropiación o expulsión del espacio vivido que el sujeto reconstruye, resignifica e identifica en el presente como parte de su propia historia de lugaridad. En este trabajo se entrelazan sensibilidades que implican conocer la comuna trece por y a través del cuerpo, por lo que recordamos, (y como lo recordamos), la diferenciación, vivencias, narrativas, formas de mirar y sentir que operan como conocimientos sensibles que van trazando la urdimbre del pasado, el presente y el futuro. 
Un espacio, como se señala al principio del texto, debe ser un lugar incluyente, abierto y donde se relacionen todo tipo de pensamientos creencias e intereses; por un lado, vemos que la espacialidad se construye a partir de ordenamientos precisos con impacto positivo sobre su contexto, por otro lado, es el instrumento que tensiona la temporalidad, dirigiendo los procesos hacia el futuro, como comentaba uno de los actores, para disminuir los grados de incertidumbre que existen en la comuna trece contemporánea.

Habitar un espacio o lugar tiene múltiples connotaciones: es una experiencia estética, pero también política; un acto que puede ser meramente consumista o de resistencia. En este caso el análisis de la complejidad del espacio llamado comuna trece en Medellín aboga por las construcciones de sociedades y lugares con mayor relación e interacción entre personas, barrios y lugares donde la gente trabaja y vive lo simple.

La espacialidad se propone en este trabajo como la cualidad o grado de lo compartido por un colectivo que se construye con nexos inteligibles por la mayoría, grado de lo que une a un colectivo. Escenarios como la comuna trece de Medellín pugnan por superar la arquitectura del distanciamiento, favoreciendo la relación cultural e identitaria e invitan a soslayar al lugar turístico por excelencia, o, a lugares que aparentan ser lo que no son; en fin, ligerezas en boga de otras espacialidades contemporáneas.

\section{Agradecimientos}

Los intereses intelectuales mostrados en este artículo intentan describir algunas tensiones de la espacialidad urbana contemporánea. El resultado obtenido obedece a una estancia de investigación doctoral que se realizó en la Universidad de Medellín y que contempla a los lugares en su multifactorialidad. Sin duda el reconocimiento principal por esta ocasión es a ese cuerpo en constante construcción llamado ciudad, cuerpo que posibilita a la vez tantas alternativas como problemáticas, y que, para su acceso sugiere el fundamento de la multi/inter/ trans disciplinariedad, sea este trabajo un aporte a las líneas investigativas que comentan y estudian los lugares y las ciudades en su esplendor y que pugnan por reconocer la importancia de comportamientos éticos vinculados a la libertad científica y creativa.

\section{Referencias}

Bustos, R. (2001). Identidad, turismo y territorios locales. La permanente construcción de valores territoriales. Aportes y transferencias. Tiempo Libre, Turismo y Recreación 5(1), 11-28. http://nulan. mdp.edu.ar/244/ 
De Certeau, M., Girad, L. y Mayol, P. (1998). The Practice of Everyday Life Vol 2 Living and cooking. University of Minnesota Press.

García, N. (2009). Culturas híbridas. Estrategias para entrar y salir de la modernidad. Fondo de Cultura Económica.

García, N. (1997). La globalización Imaginada. Paidós.

Hiernaux, D. (2000). La fuerza de lo efímero. Apuntes sobre la construcción de la vida cotidiana en el turismo. Anthropos.

Lefebvre, H. (1991). La production de l'espace. Anthoropos.

Pedone, C. (2004). Tú siempre jalas a los tuyos. Cadenas y redes migratorias de las familias ecuatorianas hacia España [tesis doctoral, Universidad Autónoma de Barcelona]. Dipòsit digital de documents de la UAB. https://ddd.uab.cat/record/36585

Rivas, D. y Mercerón, I. (2020). Prácticas de crianza, legado cultural afrodescendiente. Narrativas de mujeres afrovenezolanas. Ciencias Sociales y Educación, 9(18), 57-84. https://doi.org/10.22395/ csye.v9n18a3

Szurmuk, M. y Mckee, R. (2009). Diccionario de estudios culturales latinoamericanos. Siglo XXI editores. Instituto Mora.

Tamayo, S. y Wildner, K. (2005). Identidades urbanas. Editorial UAM. 